\title{
THE INFLUENCE OF THE ENTERPRISE LIFE CYCLE ON THE EFFICIENCY OF INVESTMENT
}

\author{
Viktor Koval' \\ Odessa Institute of Trade and Economics of Kyiv National University of Trade and Economics, Ukraine
}

\author{
Yuliia Prymush ${ }^{2}$, Viktoriia Popova ${ }^{3}$ \\ Prydniprovska State Academy of Civil Engineering and Architecture, Ukraine
}

\begin{abstract}
The article presents results of the study of relations between the enterprise life cycle and the efficiency of investment in the context of dynamic, rapid changes in the conditions of enterprises operation and development. It is determined that one of the main factors of success is the introduction of innovative technologies in the production process, which cannot be carried out without attracting investments. It is the investment activity of enterprises that determines the dynamics of their development, the level of competitiveness and the growth of productive resources, which affects the efficiency of their activities. It is proved that it is relevant to take into account the possible negative effects of the influence of factors divergence. The purpose of the study is to analyse possibilities of determining the impact of life cycle stages on the efficiency of investing in an enterprise. The methodological basis of the research is grounded on the general scientific methods of dialectics, observation, measurement, and formalization; methods of the system and statistical analysis. In particular, to determine the influence of internal factors on the indicators of the efficiency of investment activity of the enterprise at the stages of its life cycle, deterministic factor analysis is applied; methods of systematization and synthesis, analysis and synthesis are also used. It is determined that the construction industry plays a special role in the national economy since its development creates a synergistic effect for the development of other industries, increases the standard of living of the society through solving certain socioeconomic problems. The analytical data of construction enterprises activity in Dnipropetrovsk and Odesa regions of Ukraine became the basis for the approbation of the proposed approach. The use of the life cycle model of the enterprise, which includes the stage of growth (slow and rapid growth, stability stage) and the stage of the fall (slow and rapid fall, crisis stage), is substantiated. The features of investment activity according to the given stages of the life cycle of the enterprise are considered. It is determined that the growth and fall stages have a different effect on the nature of the investment indicators, which depends on certain factors. Further research is aimed at improving the mechanism of monitoring the environment in order to determine the force of factors influence on investment activity and implementation of preventive measures. The lack of a rapid reaction of the company to changes in the environment can lead to a crisis state of management, which determines the high degree of significance of adaptation for any life cycle of the enterprise.
\end{abstract}

Key words: enterprise life cycle, investment, stages of growth and fall.

JEL Classification: D15, D25

\section{Introduction}

Transformational changes in the global economy of the last decade have significantly changed the economic, legal, and social environment of the manufacturing sector of any country. There are dynamic, rapidly changing unique conditions of enterprises operation and development, in which one of the main factors of success is the introduction of innovative technologies in the production process. In order to meet the current world standards, any industry has faced an urgent need for innovation and technological change that cannot be made without investment. It is the investment activity

\footnotetext{
Corresponding author:

${ }^{1}$ Department of Applied Economics, Odessa Institute of Trade and Economics of Kyiv National University of Trade and Economics.

E-mail: victor-koval@ukr.net

${ }^{2}$ Department of Accounting, Economics and Human Resources Management of Enterprise, Prydniprovska State Academy of Civil Engineering and Architecture.

E-mail: Golovkoyuliya3@gmail.com

${ }^{3}$ Department of Accounting, Economics and Human Resources Management of Enterprise, Prydniprovska State Academy of Civil Engineering and Architecture.

E-mail: denalli.com.ua@gmail.com
} 
of enterprises that determines the dynamics of their development, the level of competitiveness and the growth of productive resources, which then affects the efficiency of their activities.

It should be noted that the economic growth of enterprises is in certain limit values of the time interval associated with the laws of cyclical functioning of the economy. The identification of the life cycle stage and the assessment of the achieved results at certain stages in order to determine the effectiveness of investment is objectively necessary for the enterprise, regardless of the scale of activity, duration of its life, size, ownership, to avoid violations of reliability and stability of its functioning. In the conditions of constant transformation of the external environment during investment, there is a problem of taking into account the possible negative consequences of the adverse effects of the said environment and the associated uncertainty and risk, which affect the reliability of the entire investment process. Therefore, the approach to the company as a dynamic system and the study of the impact of its life cycle stages on the efficiency of investment is highly relevant.

\section{Review of theory and literature}

Regularities and trends of the cyclical development of the enterprise, features of its state depending on the stage of the life cycle, the issue of determining the nature and evaluation of the enterprise life cycle were considered in the publications by A. Alti (2003), A. Downs (1967), B. Gerasimov, T. Konovalova, S. Spiridonov and N. Satalkina (2008), K. Cameron and R. Quinn (2001), D. Miller and P. Friesen (1984), B. Jovanovic and Glenn M. MacDonald, (1994), I. Ivashkovskaya and D. Yanhel (2007) and others.

Despite numerous scientific papers devoted to the study of the stages of a company life cycle, the theoretical foundations of this problem have not yet been fully disclosed. There are also a number of unresolved issues related to the quantification of the investments effectiveness and taking them into account in terms of economic substantiation of the investment reliability. In the current research of investment effectiveness, the stage of enterprise stability is the most frequently analysed, while due attention is not paid to the indicators of the previous stages and accounting for future stages of the cycle. In some cases, the economic substantiation of the reliability of investment is not carried out at all, while in others, the probabilistic nature of the environmental parameters is not considered. Thus, the need to determine the impact on the effectiveness of investment processes in the various stages of the company's life cycle predetermined the purpose of the study, which is to analyse the possibility of defining the impact of life cycle stages on the efficiency of investing in the enterprise.

\section{Data collection (data sources and methodology)}

The theoretical and methodological basis of the research was the scientific works by the leading Ukrainian and foreign scientists on the enterprise economy, assessment of stages of the life cycle of the enterprise, as well as the reliability and investment activity of the enterprise. In the process of research, the general scientific methods of dialectics, observation, measurement, and formalization were used; methods of system, statistical and graphical analysis. In particular, to determine the influence of internal factors on the efficiency indicators of the enterprise investment activity at the stages of the life cycle, deterministic factor analysis was applied; methods of systematization and synthesis, analysis and synthesis were also used. The preliminary analysis shows that the construction industry plays a special role in the national economy, since its development creates a synergistic effect for the development of other industries, increases the standard of living of society through solving certain socioeconomic problems. This formed the information base for the approbation of the proposed approach, analytical data on the activity of the construction enterprises of Dnipropetrovsk and Odesa oblasts of Ukraine.

\section{The theoretical and methodological basis of research}

One of the main engines of growth and qualitative development of the enterprise is its investment activity. Due to efficient capital expenditures, the desired growth rates are achieved, as well as the return on investment. It is obvious that improving the current technical equipment of the company will lead to an increase in the efficiency of the production process, and investment in new products development or improving the characteristics of existing goods will strengthen the market position of the enterprise, the emergence of strong competitive advantages and, consequently, will increase the value of the entire business.

According to the results of the analysis and generalization of theoretical approaches to the definition of the enterprise life cycle, despite a significant number of scientific works devoted to the issues of the life cycle by both foreign and domestic scientists, it was revealed that today there is no a single approach to the interpretation of this category. Both the content and the choice of alternatives to the life cycle of the enterprise, as well as the specific directions of its formation, depend on the content entering this concept and criteria accepted as a basis.

Category "life cycle" is one of the key economic concepts, but the essence of this definition is interpreted by different researchers quite broadly, depending on the subject which is being explored. The generally accepted definition states that "an enterprise life cycle" is a set of stages, which the 
enterprise passes during the course of its life from creation to liquidation. This is explained by the complexity and versatility of the life cycle as a phenomenon.

With regard to the research on relations between investment and the stages of an enterprise life cycle, most of the existing research in this area is focused on assessing the reliability of the enterprise as an economic system, which is determined by the diagnosis of all levels of financial and economic activity of the organization. This approach is acceptable for the enterprises at the stage of sustainable development of the life cycle trajectory. In the case when the company develops a strategic development plan and plans appropriate investments, there is a problem determining the comprehensive reliability of obtaining expected indicators assessing the economic efficiency of the future outcome. Very often, and this is noted in the literature on the analysis of the investments efficiency, there are problems with the choice of alternative investment options in comparison of their performance indicators, which are known to have different dimensions and therefore cannot be considered as an additive at different life cycle stages.

It should be noted that none of the existing models in economic science allow conducting a complete study of the enterprise life cycle, since each enterprise has its own individual pace of development, and changing the stages of the life cycle depends on a number of factors (external environment of the enterprise, branch affiliation). For our study, we offer to use the following model of the enterprise life cycle identifying: a growth stage characterized by slow and rapid growth part, a stage of stability; a stagnant phase characterized by a slow and rapid fall, and also a stage of a crisis. This choice is based on the fact that in this model, in our opinion, the basic laws of the enterprise life cycle are the most clearly traceable (Strobl \& Kronenberg, 2016).

There are several disadvantages of practical application of the methodological approaches existing in the economic literature to the definition of stages of an enterprise life cycle:

- identification of the stages of the company lifecycle is carried out on the basis of one or two indicators, which determines the narrow target orientation;

- almost all methods at the final stage of calculation are based on methods of expert evaluation;

- none of the approaches consider an enterprise life cycle as a combination of a certain ratio and interaction of the enterprise;
- each of the methods and approaches has its own limitations because there are sectorial and regional features of enterprises and it is not always possible to give an accurate qualitative and quantitative description of a particular life cycle parameter.

All this led to the need for a comprehensive approach to assessing the life cycle of a construction company, which allows:

- considering an enterprise life cycle as a set of all activities of the enterprise, subject to the influence of factors of the operational environment of the enterprise; - taking into account the ability of the company to operate at the stages of the life cycle to produce certain results; - forming an information base for the development of appropriate evaluation tools, for example, the matrix of determining the stages of the company life cycle by the indices of changes in profitability indicators (Table 1)

As noted in (Cameron and Quinn, 2001; Ivashkovskaya and Yanhel, 2007), the change in the stages of the company life cycle is determined not by the individual values of the selected indicators, but by the growth (index) of these indicators. According to the purpose of our research, the most interesting for us is the characteristic of investment activity according to the given stages of the enterprise life cycle.

Stage of growth. One of the rationales for investing in the enterprise is associated with the conditional transition from the stage of fall to a new cycle of the life cycle. First, it is a question of updating the active elements of fixed capital (Ivashkovskaya and Yanhel, 2007). Their moral aging leads to potential costs that arise as a result of the need to introduce new developments and qualitatively other means of production. In this case, an enterprise must calculate when it will be necessary to prematurely change capital assets to their full physical deterioration. Thus, a new cycle of a company begins precisely from the moment the investment project is implemented, for example, such as the replacement of the worn equipment or investment in research work.

Innovation is often seen as the starting point of the financial cycle of the whole industry (and with it and the existing enterprises in the industry). Thus, Boyan Jovanovic and Glenn M. McDonald (1994), analysing the automotive tires industry in the USA from 1906 to 1971, using a formal mathematical model, came to the conclusion that the enterprises that had first introduced new developments in 1910-1920, significantly won in growth rates (Jovanovic and MacDonald, 1994).

Table 1

Matrix identifying the stages of the company life cycle by indexes of changes in profitability indicators

\begin{tabular}{|l|c|c|c|c|c|c|}
\hline & \multicolumn{3}{|c|}{ Stage of growth } & \multicolumn{3}{c|}{ Stages of fall } \\
\hline Index of change in profitability & Slow growth & Fast growth & Stability & Slow fall & Fast fall & Crisis \\
\hline Operational activity & $\uparrow$ & $\uparrow$ & $\uparrow$ & $\downarrow$ & $\downarrow$ & $\downarrow$ \\
\hline Investment activity & $\downarrow$ & $\uparrow$ & $\uparrow$ & $\uparrow$ & $\downarrow$ & $\downarrow$ \\
\hline Financial activity & $\downarrow$ & $\downarrow$ & $\uparrow$ & $\uparrow$ & $\uparrow$ & $\downarrow$ \\
\hline
\end{tabular}

Source: developed by the authors 
The peculiarity of this stage is also that the company has to simultaneously support the growth of the production scale and invest in the qualitative transformation of business. So A. Alti in his research notes that the sensitivity of investment to the cash flow is significantly higher for young and growing firms (Alti, 2003).

Next, the growth stage is characterized by an increase in the investment stability of the organization, increase in the number of potential investors by reducing uncertainty and increasing monitoring of risks. Increasing risk controlleads to a lowering of the threshold of profitability and, therefore, requirements for the minimum efficiency of the projects under consideration. It expands the range of affordable investment projects and accelerates their implementation.

Stage of fall. Firstly, the value of the enterprise at this stage is formed entirely current (already existing assets). Secondly, enterprises in the downturn stage must have an excessive share of debt that is to be overlevered, which is equivalent to becoming bankrupt in the future. Therefore, it can be assumed that the deterioration of the enterprise development prospects will undoubtedly have a negative impact on investment policy: indirectly by reducing sources of funding and directly by concentrating investments to restore or maintain market positions. However, one should not forget that under effective management, the company will not stay on the stage for a long time and will begin to take all necessary steps to revive the business, which in turn will require additional capital investments.

It should be noted that the growth and fall stages have a different effect on the nature of certain financial indicators of investment. It depends, first of all, on the nature of the production process, the organization of management, the degree of uncertainty, prospects of development, and many other factors.

\section{The approbation of the proposed approach}

As a result, analysing the current economic state of the Ukrainian construction market, we selected ten companies from Dnipropetrovsk and Odesa regions that represent the small and medium business of the regions. The influence of external factors of the enterprises' direct and indirect environments on their life cycle has been studied (a detailed list of factors is given in (Prymush, 2013). To determine the degree of influence of the selected external factors on the types of activities of the enterprises under investigation, an elasticity coefficient was applied, which allowed obtaining the data sensitivity the efficiency indicators of the enterprises investment activity at the stages of the life cycle to the influence of the external environment (in the case of a change in the value of the external factor by $1 \%)$ :

$$
K E=\left|\frac{\frac{P_{(x) t}-P_{(x) t-1}}{P_{(x) t-1}}}{\frac{X_{t}-X_{t-1}}{X_{t-1}}}\right|,
$$

where, KE - elasticity coefficient;

$\mathrm{P}_{(\mathrm{x}) \mathrm{t}}, \mathrm{P}_{(\mathrm{x}) \mathrm{t}-1}-$ profitability indicator $\mathrm{x}$ enterprise activity at stages of the life cycle in the periods $t$ and $t-1, \%$;

$X_{t}, X_{t-1}$ - external factor of the environment of the enterprise operation in periods $\mathrm{t}$ and $\mathrm{t}-1, \%$;

$\mathrm{P}_{(\mathrm{x})}, \mathrm{X}>0$.

As a result of the calculations of the influence of external factors on the performance indicators of the investment activity of the construction enterprises in the Dnipropetrovsk and Odesa regions at the stages of the life cycle, it was determined which ones of the list have the greatest influence (Table 2). When calculating for more substantiated conclusions, the overall elasticity coefficients (for 2010-2016) for each external factor for selected enterprises were calculated as a geometric average.

Table 2

The value of elasticity coefficients for the investment activity of construction enterprises of the Dnipropetrovsk region

\begin{tabular}{|c|c|c|c|c|c|c|c|c|c|c|c|}
\hline \multirow{2}{*}{ № } & \multirow{2}{*}{ The external factor of influence } & \multicolumn{10}{|c|}{ Enterprise number } \\
\hline & & 1 & 2 & 3 & 4 & 5 & 6 & 7 & 8 & 9 & 10 \\
\hline & Factors of the immediate environment & \multicolumn{10}{|c|}{ Inverse dependence } \\
\hline 1 & $\begin{array}{l}\text { Index of the number of buildings and } \\
\text { engineering structures of unfinished } \\
\text { construction (\%, before the previous year) }\end{array}$ & 0,69 & 0,73 & 0,39 & 1,35 & 0,64 & 0,99 & 0,93 & 0,69 & 1,50 & 0,76 \\
\hline 2 & $\begin{array}{l}\text { Index of prices of manufacturers of machinery } \\
\text { and equipment (\%, before the previous year) }\end{array}$ & 2,28 & 2,40 & 2,0 & 1,57 & 1,37 & 2,06 & 2,45 & 2,09 & 1,89 & 1,78 \\
\hline \multirow[t]{2}{*}{3} & $\begin{array}{l}\text { The investment index in residential construction } \\
\text { (\%, before the previous year) }\end{array}$ & 1,58 & 1,26 & 1,68 & 1,67 & 1,26 & 1,78 & 1,46 & 1,78 & 1,57 & 1,46 \\
\hline & Factors of the indirect environment & \multicolumn{10}{|c|}{ Direct dependence } \\
\hline 4 & $\begin{array}{l}\text { Index of growth of the average official rate of the } \\
\text { national currency to foreign currencies }\end{array}$ & 1,38 & 1,0 & 1,32 & 1,65 & 0,86 & 1,48 & 1,10 & 1,42 & 1,75 & 0,96 \\
\hline 5 & $\begin{array}{l}\text { The cost of long-term loans for economic } \\
\text { entities, \% }\end{array}$ & 0,50 & 0,64 & 0,32 & 0,52 & 0,32 & 0,60 & 0,54 & 0,32 & 0,42 & 0,22 \\
\hline
\end{tabular}

Source: calculated by the authors 
The results of analysing the influence of external factors on the investment activity of construction enterprises of Dnipropetrovsk and Odesa regions at different stages of their life cycle identify the factors of the immediate functioning environment as being the most affluent; in particular:

- a significant elastic bond is observed in both regions between the indicator of the efficiency of enterprises investment activity and the prices of machinery and equipment manufacturers. Taking into account the fact that this is inverse dependence, the increase in prices will contribute to reducing the demand of construction enterprises for these funds, and as a result of the aging of non-current assets and a drop in profits from the enterprise investment activity;

- a certain connection is observed between the indicators of the efficiency of enterprises investment activity and indicators of investment in housing construction. This is determined with the fact that investment increase in fixed assets of construction enterprises leads to an increase in non-current assets, expansion of production volumes, sales of construction products and profit from investment activity of a construction company;

- significant feedback is observed between the indicator of the number of buildings and facilities under construction and the indicator of the investment activity effectiveness. This is primarily reflected in the fact that an increase in the number of uncompleted construction decreased sales of construction products and resulted in reduced investments, as the company reduces the volume of operations.

\section{Conclusions}

To sum up, it should be noted that the definition of the current phase of the life cycle is a complex process, as an enterprise may not be on the first helix of its development. It is likely that the company has already undergone one or more transformations in its development. This problem is levelled by conducting a dynamic analysis of the enterprise development from the initial stage - the stage of origin. In this case, you can get a comprehensive idea not only about the financial status of the subject of economic activity at each particular moment but also about the temporary evolution of the entire production process. It is worth noting that in order to model the empirical dependence, especially on a large studied group, it is practically impossible to detect fake stages of growth.

On the other hand, changes occurring in the external environment affect the life cycle of an enterprise by causing a significant inconsistency of the internal environment with external requirements. Therefore, further research will be aimed at improving the mechanism of monitoring the environment in order to determine the force of influence of the factors on investment activity and implementation of preventive measures. The lack of a rapid reaction of the company to the changes in the environment can lead to a crisis state of management, which determines the high degree of significance of adaptation for any enterprise life cycle.

\section{References:}

Alti, Aydogan (2003). How sensitive is investment to cash flow when financing is frictionless? The Journal of Finance, 58(2): 707-722.

Downs, A. (1967). The life Circle of Bureaus. In A. Downs (Ed.), Inside Bureaucracy. San Francisco: Little, Brown, 296-309.

Gerasimov, B.I., Konovalova, T.M., Spiridonov, S.P., \& Satalkina, N.I. (2008). Comprehensive economic analysis of the financial and economic activities of the organization. Tambov: Publishing house of Tamb. state. tech. university, 160.

Jovanovic, Boyan, \& MacDonald, Glenn M. (1994). The Journal of Political Economy, 102 (2): 322-347.

Cameron, Kim S., \& Quinn, Robert E. (2001). Diagnosis and change in organizational culture. SPb. y dr.: Pyter, 320.

Miller, D. A., \& Friesen, P. H. (1984). Longitude study of the corporate life cycle. Management science, 30: 1161-1183.

Prymush, Yu. S. (2013). Estimation of the influence of external factors on the life cycle of construction enterprises. Ekonomichnyy prostir. 77, 201-213.

Strobl, Andreas, \& Kronenberg, Christopher (2016). Entrepreneurial networks across the business life cycle: the case of Alpine hospitality entrepreneurs. International Journal of Contemporary Hospitality Management,(28) 6: 1177-1203, https: //doi.org/10.1108/IJCHM-03-2014-0147

Ivashkovskaya, I. V., \& Yanhel, D. O. (2007). The organization's life cycle and the aggregate growth rate. Korporatyvnye fynansy, 4: 97-110. 